\title{
Comparison of Mercury Level of Cord Blood in Term and Preterm
}

\section{Neonates}

\author{
Nastaran Khosravi ${ }^{1}$, Abulhassan Divband ${ }^{2}$, Nasrin Fathabadi ${ }^{3}$, Nasrin Khalesi ${ }^{1}$, Manije Sahlani ${ }^{4}$, \\ Monireh Monfaredi ${ }^{5}$ and Arash Bordbar ${ }^{1, *}$ \\ ${ }^{1}$ Pediatrics Department, Iran University of Medical Sciences, Tehran, Iran \\ ${ }^{2}$ Pediatrics Department, Hormozgan University of Medical Sciences, Bandar Abbas, Iran \\ ${ }^{3}$ National Radiation Protection Department, Iran Nuclear Regulatory Authority, Tehran, Iran \\ ${ }^{4}$ Operating Room, Akbarabadi Hospital, Tehran \\ ${ }^{5}$ Department of Biology, Shahid Beheshti University of Medical Sciences, Tehran, Iran \\ "Corresponding author: Pediatrics Department, Iran University of Medical Sciences, Tehran, Iran. Tel: +98-912548341, Email: drarashbordbar@gmail.com
}

Received 2017 May 14; Revised 2019 June 21; Accepted 2020 January 12.

\begin{abstract}
Background: Mercury is a one of the pollutant that can cross the placenta. Contamination by mercury in mothers and their neonates is associated with many problems.

Objectives: This study aimed to compare mercury levels of cord blood in term and preterm neonates in Akbarabadi Hospital, Tehran, Iran, 2014.

Methods: In this analytical cross-sectional study, we evaluated 50 term and 50 preterm neonates who were born in Akbarabadi Hospital in 2014. Necessary information including mother's age, location, mother's job, use of amalgam, use of fish, use of blood products and level of mercury were collected. Data were entered into SPSS V.16 and analyzed.

Results: Mean age of mothers was $30.1(\mathrm{SD}=6.4$ ) years. Location in $86(86 \%)$ were Tehran and in $14(14 \%)$ were out of Tehran. Mean of mercury in neonatal cord blood was $2.7(\mathrm{SD}=1.3) \mu \mathrm{g} / \mathrm{L}$. There was significant difference between this mean in term and preterm neonates (Pvalue $=0.009)$, while mean of mercury level in term neonates was $2.3(\mathrm{SD}=0.7) \mu \mathrm{g} / \mathrm{L}$ and in preterms was $3(\mathrm{SD}=1.7) \mu \mathrm{g} / \mathrm{L}$. Mean of using fish in term neonates was1.2 $(\mathrm{SD}=1.3)$ and in preterms was $1.6(\mathrm{SD}=2.5)$. We could not find any significant difference between mercury level and using amalgam, fish and blood products in term and preterm neonates (P value $>0.05$ ).

Conclusions: Mercury level of cord blood in our study was higher compared to other studies, although it is not in the level of toxicity. Also we found that mercury level in preterm neonates is significantly higher than term neonates, therefore evaluating factors affecting mercury levels in neonates is essential.
\end{abstract}

Keywords: Neonate, Term, Preterm, Mercury

\section{Background}

Mercury is an odorless, silvery white, shiny, electric, heat insulating heavy metal, and there is a large amount of this metal in the outside environment and sea foods (1). It is a one of the pollutants which has well-characterized neurodevelopmental toxicity (2). Commonly, exposures to mercury are first to methylmercury ( $\mathrm{MeHg}$ ) through use of infected fish (2,3). Many maternal conditions during pregnancy can affect the newborn (4). Exposures during prenatal and perinatal period are an important concern because mercury can cross the placenta $(5,6)$. There is a positive correlation of $\mathrm{Hg}$ in paired maternal/fetal samples (7). Studies on laboratory animals have shown that in mothers who had exposure to mercury, the amount of this metal in the liver of the fetus reached the level that concluded mercury can freely pass the placenta (1).

The human body is exposed to mercury through the environment, atmosphere, dental amalgams, and diet especially fish (3). Mercury poisoning can be described as an event that does not occur normally, but when it happens it can be risky and problematic (8). Mercury poisoning is demonstrated with symptoms such as pain, erythema in palms and feet, irritability, sleeplessness, loss of appetite, excessive sweating, sensitivity to light and skin rash $(8,9)$.

Urinary mercury concentrations above $20 \mu \mathrm{g} / \mathrm{L}$, should be considered as high level, although there is no precise and absolute relationship between urinary mercury concentrations and clinical symptoms. Mercury levels higher than $150 \mu \mathrm{g} / \mathrm{L}$ are associated with non-specific symptoms and in the level of higher than $300 \mu \mathrm{g} / \mathrm{L}$ clear and specific 
signs are seen $(8,10,11)$. Mercury levels in blood, not in serum; in general population is typically less than $5 \mu \mathrm{g} / \mathrm{L}$ (12).

Although moderate mercury levels in pregnancy were not associated with anthropometric variables, or on the odds of low birthweight or preterm birth (13), but consumption of seafood with high levels of mercury during pregnancy can cause a decrease in the evolution of the nervous system (14). Also pollution with high levels of mercury in postpartum is associated with defects in the nervous system (15); although research on people who are involved with amalgam in workplace or mothers who fill their teeth during pregnancy does not show a discernable effect on risk of spontaneous abortions, birth defects or reduced birth weight $(16,17)$. Exposure to toxic mercury in children may lead to the impairment of the developing central nervous system and pulmonary as well as nephrotic damage.

\section{Objectives}

Despite the importance of this issue, very little studies on mercury levels in cord blood of newborn infants has been conducted. This study aimed to compare mercury levels of cord blood in term and preterm neonates in Akbarabadi Hospital in Tehran, Iran, 2014.

\section{Methods}

This research was an analytical cross sectional study which was done on newborn babies who were referred to Shahid Akbarabadi Hospital in 2014. All infants who had inclusion criteria were recruited in this study until the completion of sample size. Inclusion criteria consisted of mother's consent to participate in research projects, singleton pregnancy, maternal age between 18 to 35 years, number of pregnancies of less than 3 , and no evidence of genetic and chromosomal defects. Patients were excluded if there was sonographic evidence of growth defects, history of stillbirths and abortions in mothers and history of preeclampsia in a previous pregnancy, mothers who consumed a special drug that had an effect on the response, as well as mothers who had a specific illness were excluded from the study. Also, those pregnant women that filled at least two teeth before pregnancy were examined. Those who filled during pregnancy or filled maximally one tooth were excluded.

Finally, after evaluating infants from the point of these criteria, 50 term and 50 preterm newborn babies were recruited in this study and were evaluated. The sample size was calculated according to the findings of previous studies considering the significance level of 0.05 and the standard deviation of 1.9.

The consumption of fish and other variables in pregnant women was assessed using a checklist.

This checklist which included necessary variables such as maternal age, location, job, amalgam use, consumption of fish and use of blood products during pregnancy was completed for each patient. We examined pregnant women who consumed fish at least once a week. Women who consumed less than this amount of fish were excluded.

A sample of the infant's cord blood was taken after the birth and sent to laboratory for measurement of mercury levels. Mercury levels were determined using atomic absorption spectrometry.

Data were entered into SPSS V.16 and analyzed. Mean, standard deviation (SD) and frequency was used as descriptive analysis. For evaluation the distribution of data, onesample Kolmogorov-Smirnov test was used. Qualitative data were compared with chi-square test. Student $t$-test was used to compare quantitative variables.

It should be noted that all the provisions of the Helsinki Declaration on research projects have been respected in this study.

\section{Results}

Fifty preterm and 50 term infants were evaluated. Mean age of mothers was $30.1(\mathrm{SD}=6.4)$. Mothers' mean age in term infants was $30(\mathrm{SD}=6.2)$ and in preterm mothers was $30.4(\mathrm{SD}=6.7)$ which was not statistically significant ( $\mathrm{P}$ value $>0.05)$. More results are presented in Table 1.

As shown in Table 1, the location in 86 (86\%) (42 (84\%)) of term infants and 44 (88\%) of preterm infants) was in Tehran and $14(14 \%)$ ( $8(16 \%))$ of term infants and $6(12 \%)$ of preterm infants) lived out of Tehran in Sharyar, Varamin or Eslamshahr.

In all term neonate mothers were housewives, but in preterm group 45(90\%) of mothers were housewives, 3(6\%) were nurses, $1(2 \%)$ was tailor and $1(2 \%)$ was an employee.

Mean of mercury level in infants was $2.7(\mathrm{SD}=1.3) \mu \mathrm{g} / \mathrm{L}$. Minimum amount of mercury level was 0.5 and maximum level of it was $6.6 \mu \mathrm{g} / \mathrm{L}$. We found significant difference between mean of mercury level in umbilical cord in term and preterm infants $(\mathrm{P}$ value $=0.009)$; while this mean in term infants was $2.3(\mathrm{SD}=0.7) \mu \mathrm{g} / \mathrm{L}$ and in preterm infants was $3(\mathrm{SD}=1.7) \mu \mathrm{g} / \mathrm{L}$. Figure 1 compares these means. The minimum amount in term infants was $0.5 \mu \mathrm{g} / \mathrm{L}$ and maximum amount was $4.2 \mu \mathrm{g} / \mathrm{L}$. Minimum amount in preterm infants was $1 \mu \mathrm{g} / \mathrm{L}$ and maximum amount was $6.6 \mu \mathrm{g} / \mathrm{L}$. No 


\begin{tabular}{|c|c|c|c|}
\hline Outcome Variable & Term Infants & Preterm & P Value \\
\hline Age & $30 \pm 6.2$ & $30.4 \pm 6.7$ & 0.76 \\
\hline Location & & & 0.77 \\
\hline Tehran & $42(84)$ & $44(88)$ & \\
\hline Out of Tehran & $8(16)$ & $6(12)$ & \\
\hline Mercury level & $2.3 \pm 0.7$ & $3 \pm 1.7$ & 0.009 \\
\hline Fish consumption & $1.2 \pm 1.3$ & $1.6 \pm 2.5$ & 0.32 \\
\hline \multicolumn{4}{|l|}{ Use of amalgam } \\
\hline Yes & $17(34)$ & $17(34)$ & 1 \\
\hline No & $33(66)$ & $33(66)$ & \\
\hline Filled teeth & $2.3 \pm 1.3$ & $2.4 \pm 1.1$ & 0.68 \\
\hline Use of blood products & & & 1 \\
\hline Yes & $0(0)$ & $1(2)$ & \\
\hline No & $50(100)$ & $49(98)$ & \\
\hline
\end{tabular}

${ }^{\mathrm{a}}$ Values are expressed as No. (\%) or mean $\pm \mathrm{SD}$.

term infants had mercury level of higher than $5.8 \mu \mathrm{g} / \mathrm{L}$, but in $4(8 \%)$ of preterm infants, this level was higher than 5.8 $\mu \mathrm{g} / \mathrm{L}$.

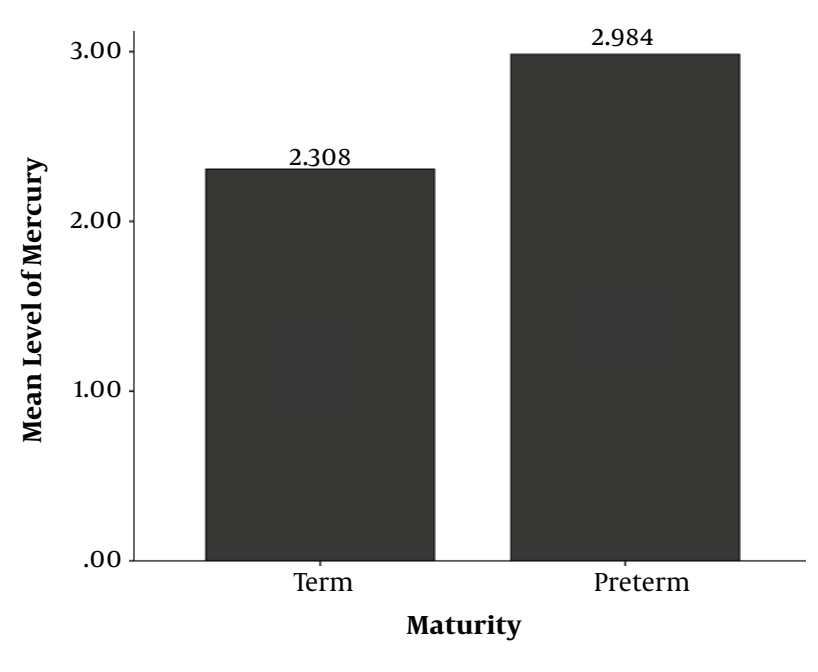

Figure 1. Comparison of mercury level between term and preterm infants

Mean number of fish consumption in term infants was $1.2(\mathrm{SD}=1.3)$ and in preterm infants was 1.6 $(\mathrm{SD}=2.5)$. Seventeen (34\%) mothers in both term and preterm group used amalgam. Mean number of filled teeth in term infants' mothers was $2.3(\mathrm{SD}=1.3)$ and in preterm infants' mothers was 2.4 ( $\mathrm{SD}=1.1)$, which was not significant in these two groups (Pvalue $>0.05)$.

From all studied mothers, 1(2\%) in preterm group used blood products due to addiction. There was not any significant difference between level of mercury and usage of amalgam or blood products in term and preterm infants (P value $>0.05)$

\section{Discussion}

Levels of mercury in umbilical cord of 50 term and 50 preterm infants were evaluated. Based on our results, mean of mercury level was on average $2.7(\mathrm{SD}=1.3) \mu \mathrm{g} / \mathrm{L}$ in studied population. The mean was $2.3(\mathrm{SD}=0.7) \mu \mathrm{g} / \mathrm{L}$ in term and $3(\mathrm{SD}=1.7) \mu \mathrm{g} / \mathrm{L}$ in preterm infants.

In Wells et al. (18) study in 2011, mean of mercury level in 300 infants was $1.4(\mathrm{CI}=36.7-40.6) \mu \mathrm{g} / \mathrm{L}$ that was in risk range for similar population. The King et al. (19) study in 2013 reported mean cord mercury level of $0.5 \mu \mathrm{g} / \mathrm{L}$. Mean of umbilical cord mercury level in Wu et al. (20) study in 2013 was 1.8 ( $\mathrm{SD}=1.9)$. The mean was lower than similar previous studies in these two studies $(19,20)$.

In comparison to mentioned studies, mean level of mercury in our study was higher than previous reports, although this mean is not higher than reference levels recommended by the Environmental Protection Agency (EPA) which is $5.8 \mu \mathrm{g} / \mathrm{L}$ or $29 \mathrm{nmol} / \mathrm{L}$ (21-23). Of course there are some studies with higher levels of mercury compared to the present study $(24,25)$.

In a study by Kozikowska et al. (24) in 2013, mean mercury level of cord blood, placenta and umbilical cord was $9 \mu \mathrm{g} / \mathrm{L}$. There was not any significant difference between mercury levels in different age groups. Santos et al. (25) in 2013 reported mercury level of cord blood as $16.7 \mu \mathrm{g} / \mathrm{L}$ in their research.

There was a significant difference between mercury level of umbilical cord in term and preterm infants in the present study, while the mean was higher in preterm infants. Also there were no infants in term group with a mercury level above the permitted limit, but we found 4 (8\%) preterm infants who had mercury levels higher than 5.8 $\mu \mathrm{g} / \mathrm{L}$.

In a cohort study which was done by Chen et al. (26) in 2014 , it was reported that mercury levels in preterm or low birth weight infants were significantly higher than term infants.

Mean of fish consumption in preterm infants was more than term in the present study, although this was not statistically significant. This study was conducted in Tehran which is an area away from the sea and consumption of seafood in studied mothers, is generally low. GarciaEsquinas et al. (27) in 2013 reported that mercury concentration was 25\% higher in infants of mothers who ate more fish. Wu et al. (20) also showed in their study that mercury 
concentration is associated with diet of pregnant women, especially fish, shellfish, milk and fruit.

One of our limitations was small sample size. Also studied population was evaluated in Akbarabadi Hospital. Since this hospital is located in the south of Tehran and the majority of patients had low socioeconomic level, our sample is not representative of the normal population. Due to low sample size and effective factors such as being away from the sea and similar location of mothers (mostly in Tehran), evaluation of factors affecting the level of mercury, such as fish or location, was not exactly possible, therefore further studies with a larger population in a wider geographic area is suggested for more precise results.

\subsection{Conclusions}

Mercury level of cord blood in our study was higher compared to other studies, although it is not in the level of toxicity. Also we found that mercury level in preterm neonates is significantly higher than term neonates 2.3 (SD $=0.7) \mu \mathrm{g} / \mathrm{L}$ in term and $3(\mathrm{SD}=1.7) \mu \mathrm{g} / \mathrm{L}$ in preterm $)$, therefore evaluating factors affecting mercury level in neonates is essential.

\section{Acknowledgments}

The authors would like to thank the Shahid Akbarabadi Clinical Research Development Unit (ShACRDU), Iran University of Medical Sciences (IUMS), Tehran, Iran.

\section{Footnotes}

Authors' Contribution: Arash Bordbar and Nastaran Khosravi contributed to the main idea and follow up of this study. They also contributed to the drafting of the article and ultimately approved the final version. Abulhassan Divband did gathering the data and drafting the manuscript. Nasrin Fathabadi, Nasrin Khalesi, Manije Sahlani, and Monireh Monfaredi also contributed to drafting the paper and final approval.

Conflict of Interests: The author(s) declared no potential conflicts of interest with respect to the research, authorship, and/or publication of this article.

Ethical Approval: The Ethics Committee of Iran University of Medical Sciences approved the study.

Funding/Support: There is no funding or support for this study.

Informed Consent: Informed consent was obtained from the participants.

\section{References}

1. Dock L, Rissanen RL, Vahter M. Demethylation and placental transfer of methyl mercury in the pregnant hamster. Toxicology.1994;94(13):131-42. doi: 10.1016/0300-483x(94)90033-7.

2. Zheng N, Wang S, Dong W, Hua X, Li Y, Song X, et al. The toxicological effects of mercury exposure in marine fish. Bull Environ Contam Toxicol. 2019;102(5):714-20. doi: 10.1007/s00128-019-02593-2. [PubMed: 30949738].

3. Nogara PA, Farina M, Aschner M, Rocha JBT. Mercury in our food. Chem Res Toxicol. 2019;32(8):1459-61. doi: 10.1021/acs.chemrestox.9b00126. [PubMed: 31124669].

4. Bordbar A, Farjadnia M. Maternal morbidities and occurrence of intraventricular hemorrhage in preterm infants. J Pediatr Intensive Care. 2015;4(3):156-61. doi: 10.1055/s-0035-1559825. [PubMed: 31110865]. [PubMed Central: PMC6513166].

5. Kajiwara Y, Yasutake A, Adachi T, Hirayama K. Methylmercury transport across the placenta via neutral amino acid carrier. Arch Toxicol. 1996;70(5):310-4. doi: 10.1007/s002040050279. [PubMed: 8852703].

6. Yoshida M. Placental to fetal transfer of mercury and fetotoxicity. Tohoku J Exp Med. 2002;196(2):79-88. doi: 10.1620/tjem.196.79. [PubMed: 12498319].

7. Huang SH, Weng KP, Lin CC, Wang CC, Lee CTC, Ger LP, et al. Maternal and umbilical cord blood levels of mercury, manganese, iron, and copper in southern Taiwan: A cross-sectional study. J Chin Med Assoc. 2017;80(7):442-51.

8. Shannon MW, Borron SW, Burns MJ. Haddad and Winchester's clinical management of poisoning and drug overdose. 4 th ed. United States: W.B Saunders; 2007. p. 750-6.

9. Ekino S, Susa M, Ninomiya T, Imamura K, Kitamura T. Minamata disease revisited: An update on the acute and chronic manifestations of methyl mercury poisoning. J Neurol Sci. 2007;262(1-2):131-44. doi: 10.1016/j.jns.2007.06.036. [PubMed: 17681548].

10. Ng DK, Chan $\mathrm{CH}$, Soo MT, Lee RS. Low-level chronic mercury exposure in children and adolescents: meta-analysis. Pediatr Int. 2007;49(1):807. doi: 10.1111/j.1442-200X.2007.02303.x. [PubMed: 17250511].

11. Horowitz Y, Greenberg D, Ling G, Lifshitz M. Acrodynia: A case report of two siblings. Arch Dis Child. 2002;86(6):453 doi: 10.1136/adc.86.6.453. [PubMed: 12023189]. [PubMed Central: PMC1762992].

12. Davidson PW, Myers GJ, Weiss B. Mercury exposure and child development outcomes. Pediatrics. 2004;113(4 Suppl):1023-9. [PubMed: 15060195].

13. Taylor CM, Golding J, Emond AM. Blood mercury levels and fish consumption in pregnancy: Risks and benefits for birth outcomes in a prospective observational birth cohort. Int J Hyg Environ Health. 2016;219(6):513-20. doi: 10.1016/j.ijheh.2016.05.004. [PubMed: 27252152]. [PubMed Central: PMC4970655].

14. Lederman SA, Jones RL, Caldwell KL, Rauh V, Sheets SE, Tang D, et al. Relation between cord blood mercury levels and early child development in a World Trade Center cohort. Environ Health Perspect. 2008;116(8):1085-91. doi: 10.1289/ehp.10831. [PubMed: 18709170]. [PubMed Central: PMC2516590].

15. Ramon R, Murcia M, Ballester F, Rebagliato M, Lacasana M, Vioque J, et al. Prenatal exposure to mercury in a prospective mother-infant cohort study in a Mediterranean area, Valencia, Spain. Sci Total Environ. 2008;392(1):69-78. doi: 10.1016/j.scitotenv.2007.11.025. [PubMed: 18155751].

16. Hujoel PP, Lydon-Rochelle M, Bollen AM, Woods JS, Geurtsen W, del Aguila MA. Mercury exposure from dental filling placement during pregnancy and low birth weight risk. Am J Epidemiol. 2005;161(8):73440. doi: 10.1093/aje/kwi100. [PubMed: 15800265].

17. Brodsky JB, Cohen EN, Whitcher C, Brown BJ, Wu ML. Occupational exposure to mercury in dentistry and pregnancy outcome. JAm Dent Assoc. 1985;111(5):779-80. doi: 10.14219/jada.archive.1985.0182. [PubMed: 3864842]. 
18. Wells EM, Jarrett JM, Lin YH, Caldwell KL, Hibbeln JR, Apelberg $\mathrm{BJ}$, et al. Body burdens of mercury, lead, selenium and copper among Baltimore newborns. Environ Res. 2011;111(3):411-7. doi: 10.1016/j.envres.2010.12.009. [PubMed: 21277575]. [PubMed Central: PMC3064741].

19. King E, Shih G, Ratnapradipa D, Quilliam DN, Morton J, Magee SR. Mercury, lead, and cadmium in umbilical cord blood. J Environ Health. 2013;75(6):38-43. [PubMed: 23397648].

20. Wu M, Yan C, Xu J, Wu W, Li H, Zhou X. Umbilical cord blood mercury levels in China. J Environ Sci (China). 2013;25(2):386-92. doi: 10.1016/s1001-0742(12)60061-8. [PubMed: 23596960].

21. Murata Y, Finkelstein DB, Lamborg CH, Finkelstein ME. Tuna consumption, mercury exposure, and knowledge about mercury exposure risk from tuna consumption in university students. Environ Toxicol Chem. 2019;38(9):1988-94. doi: 10.1002/etc.4513. [PubMed: 31189023].

22. Counter SA, Buchanan LH. Mercury exposure in children: A review. Toxicol Appl Pharmacol. 2004;198(2):209-30. doi: 10.1016/j.taap.2003.11.032. [PubMed: 15236954].

23. Environmental Protection Agency. Organic mercury Toxicity and Exposure Assessment for Children's Health. Environmental Protection Agency. Organic mercury, toxicity and exposure assessment for children's health. U.S: EPA; 2007. Available from: www.epa.gov/teach/chem_ summ/mercury_org_summary.pdf.

24. Kozikowska I, Binkowski LJ, Szczepanska K, Slawska H, Miszczuk K, Sliwinska M, et al. Mercury concentrations in human placenta, umbilical cord, cord blood and amniotic fluid and their relations with body parameters of newborns. Environ Pollut. 2013;182:256-62. doi: 10.1016/j.envpol.2013.07.030. [PubMed: 23938449].

25. Santos EO, Jesus IM, Camara Vde M, Brabo Eda S, Jesus MI, Fayal KF, et al. Correlation between blood mercury levels in mothers and newborns in Itaituba, Para State, Brazil. Cad Saude Publica. 2007;23 Suppl 4:S6229. doi: 10.1590/s0102-311x2007001600022. [PubMed: 18038043].

26. Chen Z, Myers R, Wei T, Bind E, Kassim P, Wang G, et al. Placental transfer and concentrations of cadmium, mercury, lead, and selenium in mothers, newborns, and young children. J Expo Sci Environ Epidemiol. 2014;24(5):537-44. doi: 10.1038/jes.2014.26. [PubMed: 24756102]. [PubMed Central: PMC4329243].

27. Garcia-Esquinas E, Perez-Gomez B, Fernandez-Navarro P, Fernandez MA, de Paz C, Perez-Meixeira AM, et al. Lead, mercury and cadmium in umbilical cord blood and its association with parental epidemiological variables and birth factors. BMC Public Health. 2013;13:841. doi: 10.1186/1471-2458-13-841. [PubMed: 24028648]. [PubMed Central: PMC3848449]. 